\title{
RETRACTED ARTICLE: Convergence Rate of Inertial Proximal Algorithms with General Extrapolation and Proximal Coefficients
}

\author{
Hedy Attouch ${ }^{1} \cdot$ Zaki Chbani $^{2} \cdot$ Hassan Riahi $^{2}$ \\ Published online: 27 January 2020 \\ c) Malaysian Mathematical Sciences Society and Penerbit Universiti Sains Malaysia 2020
}

The publisher has retracted this article [1]. Due to an operational error, this article was accidentally published in the wrong journal. The article was peer reviewed and accepted at the Vietnam Journal of Mathematics, where it will be published. The publisher apologizes for this error and any inconvenience caused. All authors agree with this retraction. The online version of this article contains the full text of the retracted article as electronic supplementary material.

\section{Reference}

1. Attouch, H., Chbani, Z., Riahi, H.: Convergence Rate of Inertial Proximal Algorithms with General Extrapolation and Proximal Coefficients. Bull. Malays. Math. Sci. Soc. (2020). https://doi.org/10.1007/ s40840-020-00900-3

Publisher's Note Springer Nature remains neutral with regard to jurisdictional claims in published maps and institutional affiliations.

Electronic supplementary material The online version of this article (https://doi.org/10.1007/s40840020-00900-3) contains supplementary material, which is available to authorized users.

$\bowtie$ Hedy Attouch

hedy.attouch@umontpellier.fr

Zaki Chbani

chbaniz@uca.ac.ma

Hassan Riahi

h-riahi@uca.ac.ma

1 IMAG, CNRS, Université de Montpellier, Montpellier, France

2 Department of Mathematics, Faculty of Sciences Semlalia, Cadi Ayyad University, 40000 Marrakech, Morocco 